Please cite this article as:

Urbinati, A., Chiaroni, D., and Chiesa, V. (2017).

Towards a New Taxonomy of Circular Economy Business Models.

Journal of Cleaner Production, Vol. 168, pp. 487-498.

(DOI: https://doi.org/10.1016/j.jclepro.2017.09.047) 


\title{
Towards a New Taxonomy of Circular Economy Business Models
}

\begin{abstract}
Circular Economy has undoubtedly become one of the hot topics in public debates about new and more sustainable industrial paradigms and strategies. In this respect, the fashion of Circular Economy is in the fact that it aims at overcoming the dominant linear take, make, disposal economy model, i.e. "a traditional open-ended economy model developed with no built-in tendency to recycle, which is reflected by treating the environment as a waste reservoir" ( $\mathrm{Su}$, et al., 2013). Circular Economy, indeed, bases on the establishment of closed production systems, where resources are reused and kept in a loop of production and usage, allowing generating more value and for a longer period. Despite the interest for Circular Economy by politicians and practitioners, scholars, particularly in the strategic management field, are still struggling with a lack of a framework explaining how companies willing to become circular adapt their existing business model or create a new one. By extensively reviewing, through the lens of business model literature, the extant contributions on Circular Economy, we propose a taxonomy of Circular Economy Business Models based on the degree of adoption of circularity along two major dimensions: (i) the customer value proposition $\&$ interface, i.e. the implementation of the circularity concept in proposing value to customers; (ii) the value network, i.e. the ways through which interacting with suppliers and reorganizing the own internal activities. The taxonomy is then initially tested through some explorative case studies, showing in practice the ability of the framework to properly distinguish different modes of adoption of Circular Economy.
\end{abstract}

Keywords: circular economy; closed-loop economy; circular economy business models. 


\section{Introduction}

Circular Economy has undoubtedly become one of the hot topics in public debates about new and more sustainable industrial paradigms and strategies (Gerrard \& Kandlikar, 2007; Geng, et al., 2009; Xue, et al., 2010; McGlyn, 2015; Vermeulen, 2015). Indeed, Circular Economy aims at transforming in depth the way we use resources, by replacing existing open production systems, i.e. systems based on a linear consumption economy model where raw materials are extracted, processed into finished products and become waste after they have been consumed, with closed production systems, i.e. new systems where resources are reused and kept in a loop of production and usage, allowing to generate more value and for a longer period (McDonough \& Braungart, 2002; Geng, et al., 2009; 2012; Xue, et al., 2010; Su, et al., 2013).

However, despite the interest for Circular Economy by politicians and practitioners, scholars, particularly in the strategic management field, are still struggling with a lack of a framework explaining how companies willing to become circular adapt their existing business model or create a new one. Indeed, the current representation of Circular Economy, i.e. the one based on macro-loops associated with the product-life extension, its redistribution and reuse, remanufacturing and recycling, does not allow distinguishing different business models, i.e. different modes of adoption of Circular Economy by companies. Even the anecdotic of Circular Economy emerging from extant literature contributions (Williams, 2006, 2007; Subramoniam, et al., 2009; Ma, et al., 2014; Li \& Ma, 2015) either refers to a whole industry or industry segment, not reflecting on the adoption by single firms, or is presented in a sort of Boolean on or off adoption, where firms are presented as they adopt any of the circular practices (e.g., redistribution and reuse, remanufacturing or recycling of products) in their internal activities, independently of the magnitude of adoption at firm-level. Accordingly, the placement of Circular Economy in the strategic management field remains unexplored and further theoretical and empirical research that provides a framework of how Circular Economy is being applied at a different extent by companies is required (Murray, et al., 2017).

In addition, if we look to extant contributions from practitioners (McKinsey, 2011; Ellen Mac Arthur Foundation, 2013; Accenture, 2014) that propose cases of companies as clear examples of Circular Economy, it does not appear evident neither the process these companies implemented to establish their circular business model, nor whether exist different typologies of circular business models they established. For instance, Renault is usually cited as an "adopter" for its redesign of the plant located in Choisy-le-Roi (France), that was purposively dedicated (in such being a sort of first of a kind in the industry) to the remanufacturing of mechanical (such as engine, alternators, or turbochargers) and electronic (such as control units or audio systems) components to be then reused 
by Renault as spare parts on new and used cars ${ }^{1}$. Similarly, PUMA has developed a new line of shoes and clothing called INCYCLETM, which consists in biodegradable or recyclable products and all certified Cradle-to-Cradle ${ }^{\mathrm{TM}}$ (Ellen Mac Arthur Foundation, 2013). These products require a redesign of each stage of their production process and changes in the choice of materials and pigments to allow chemicals degrading and not remain in the soil. Moreover, the Garment Collecting Program ${ }^{2}$ of H\&M, i.e. the result of a partnership between H\&M and I:CO, aims at collecting and propose to their customers the used clothes at the firm's stores in three ways: "(i) rewear, i.e. clothing that can be worn again will be sold as second hand clothes; (ii) reuse, i.e. old clothes and textiles will be turned into other products, such as cleaning cloths; (iii) recycle, i.e. everything else is turned into textile fibers, or other use such as insulation”. In addition, Dell - in partnership with FedEx - collects door-to-door the devices that customers want to dispose of ${ }^{3}$. Furthermore, the relationship between Patagonia and eBay, i.e. the Common Threads Initiative 4 , allows customers of the brand becoming business partners, with the goal to reduce the consumption of clothes, by extending their useful life through their repair, reuse and recycle.

However, are these truly examples of adoption of Circular Economy? Are they showing a similar idea of Circular Economy? Or rather do they highlight there are many different facets of the concept of Circular Economy and does the way firms approach this new industrial paradigm require a better understanding?

We believe there is a lack of contributions assuming the firm as a unit of analysis and the business model perspective to explain how firms adopt this new paradigm. Therefore, we retain that answering the questions above means developing a comprehensive understanding on the role that Circular Economy can play from a business model perspective. We additionally retain that this issue is even more relevant to explore nowadays when there are empirical evidences highlighting the lack of public awareness on the potential of Circular Economy and few incentives for companies to translate in practical actions the concept of Circular Economy (Xue, et al., 2010; Su, et al., 2013; Guo, et al., 2017).

\footnotetext{
${ }^{1}$ http://www.ellenmacarthurfoundation.org/circular-economy/interactive-diagram/the-circulareconomy-applied-to-the-automotive-industry.

${ }^{2} \mathrm{http} / / /$ about.hm.com/en/About/sustainability/commitments/reduce-waste/garment-collecting.html.

${ }^{3} \mathrm{http}: / / \mathrm{www} \cdot d e l l . c o m / l e a r n / \mathrm{us} / \mathrm{en} /$ uscorp1/dell-environment-recycling?s=corp.

${ }^{4} \mathrm{http}: / / \mathrm{www}$.prnewswire.com/news-releases/patagonia-launches-common-threads-initiative-a-partnershipwith-customers-to-consume-less-129372068.html.
} 
Starting from the premises above, we propose in this paper, a taxonomy of Circular Economy Business Models based on the degree of adoption of circularity along two major dimensions: (i) the customer value proposition $\&$ interface, i.e. the implementation of the circularity concept in proposing value to customers; (ii) the value network, i.e. the ways through which interacting with suppliers and reorganizing the own internal activities.

The paper is organized as follows. We first present in the State-of-the-art section (Section 2) the new industrial paradigm of Circular Economy (Section 2.1), the main research domains that have dealt with Circular Economy (Sections 2.1.1 and 2.1.2), and the business model perspective (Section 2.2). In Section 3, we depict our theoretical framework (Section 3.1) and present the empirical analysis we designed to test our taxonomy (Section 3.2). In Section 4, we discuss the results of its application to the empirical setting we created and finally, in Section 5, we point out the main implications of our study and argue about the main limitations of the paper and avenues for further research in the field of Circular Economy. 


\section{State-of-the-art}

\subsection{Circular Economy as a new industrial paradigm}

The goal of Circular Economy is to replace existing open production systems based on a linear consumption model, where raw materials are extracted, processed into finished products and become waste after they have been consumed, with closed systems that reuse resources and conserve energy (McDonough \& Braungart, 2002; Geng, et al., 2009; 2012; Xue, et al., 2010). In particular, Circular Economy aims at overcoming the dominant linear take, make, disposal economy model, which is "a traditional open-ended economy model developed with no built-in tendency to recycle, which is reflected by treating the environment as a waste reservoir" (Su, et al., 2013). Indeed, a linear economy expects that companies extract materials, apply energy to transform them into final products, sell them to consumers and, finally, throw them away when they are no longer working or no longer satisfy their needs (UNEP, 2006; Su, et al., 2013). Although over time a great progress in increasing resource efficiency has been achieved, this model incorporates various sources of waste along the entire supply chain (Murray, et al., 2017).

Circular Economy proposes a completely different approach giving a new life and a new and more comprehensive meaning to the already known concepts of closed-loop economy or cradle-to-cradle (McDonough \& Braungart, 2002; Mathews \& Tan, 2011; Kama, 2014; Murray, et al., 2017; Hu, et al., 2011). Indeed, in a Circular Economy, "the open-ended system could be and should be converted to a circular system when considering the relationship between resource use and waste residuals" ( $\mathrm{Su}$, et al., 2013). Circular Economy is normally represented by the mean of four loops (Salonitis \& Stavropoulos, 2013; Ellen MacArthur Foundation, 2013), representing four key principles for Circular Economy5: (i) product-life extension, i.e. "Products are designed to be durable and to have a long lifetime, thus reducing consumption. Such products are by definition high quality, so businesses often need to change their business model in order to offset the increase product cost, for example by leasing instead of selling products or generating revenue by selling additional services”; (ii) redistribution/reuse, i.e. "The most sustainable product is often one we already own. Reusing a product preserves all of the added-value within that product"; (iii) remanufacturing, which "is defined as series of manufacturing steps acting on an end-of-life part or product in order to return it to likenew or better performance, with warranty to match"; (iv) recycling, which is "the most common Circular Economy process through which used materials are

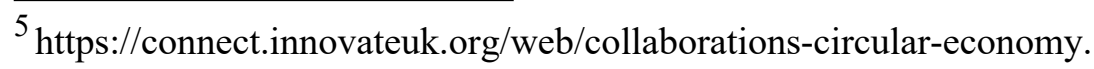


treated so as to make them suitable for reuse". It appears clearly all these principles refers to products, i.e. they assume the key unit of analysis for Circular Economy is the product itself.

Therefore, the four loops of Circular Economy underline the efficient use of products with the aim to maintain them as long as possible into the economy through product-life extension, redistribution/reuse, remanufacturing and recycling. In this case, the industrial paradigm of Circular Economy aims to reach a high value-added of products as long as possible and minimize the production of waste, as it happens in a linear production. Every loop indeed can increase its value as much as is short the loop itself, as the product is replaced in the economy with more speed and frequency.

To reach this goal, two relevant aspects of Circular Economy have to be taken into account in explaining the core contribution of value creation (and reduction of waste) in the four loops. On the one hand, companies must posit their purposive effort to the product design, with the aim to ensure an effective "disassembly for reuse" practice of product's resources, once the product finishes the useful life, or they have to clearly intervene in the supply chain management (Mayyas, et al., 2012; Go, et al., 2011; Goldsworthy, 2014; Dagman \& Söderberg, 2012; De los Rios \& Charnley, 2017). On the other hand, Circular Economy calls provider companies to extend their responsibility over the users for the ownership of products, for example, by providing products as a service, in order to enable a more effective closing of loops (retaining the ownership of products encompasses the highest level of responsibility over it) (Mayers, et al., 2005; Xue, et al., 2010; Richter \& Koppejan, 2016; Guo, et al., 2017; Fischer \& Pascucci, 2017).

\subsubsection{Circular Economy in the existing literature}

Scientific literature has already studied Circular Economy under several perspectives. The main streams of research dealing with this topic are the (i) industrial ecology, the (ii) environmental, political and social science, and the (iii) literature on the product design practices.

On the one hand, industrial ecology studies focus on the establishment of eco-industrial networks, or eco-systems, as a way to implement in practice Circular Economy, allowing the transition from traditional to circular companies (Yang \& Feng, 2008; Geng, et al., 2009). In this respect, several authors (Chertow \& Ehrenfeld, 2012; Fernandez, 2007; Lombardi, et al., 2012; Mathews \& Tan, 2011; Mattila, et al., 2012; Yu, et al., 2014; Yuan, et al., 2006; Zhu, et al., 2011) have pointed out the importance for companies to share assets at multiple levels, such as material and physical resources, local infrastructures, and recycling waste, in order to obtain mutual benefits with other partners. Benefits from this cooperative and cross-industry management of resources are 
the reduction of negative environmental externalities and the increase of positive environmental effects, such as the reduction of disposal activities through the reuse of items, the recycling of materials and components, and the remanufacturing of products. In addition, the "eco-system metaphor" has a fundamental role in shaping new strategies for companies piloted by the concept of Circular Economy, although it seems to require further investigation when there are not yet consolidated incentives, financial support and a need of a broad improvement in public awareness and participation around the activities of Circular Economy (Geng, et al., 2009; Su, et al., 2013).

On the other hand, environmental, political and social science looks at this new industrial paradigm as a way to encourage people toward more sustainable behaviors, as well as a tool for policymakers to develop Circular Economy-driven environmental and management policies and to create new regulations that incorporate principles of sustainability (Murray, et al., 2017; Preston, 2012; Besio \& Pronzini, 2014; Miliute-Plepiene \& Plepys, 2015; Schneider, 2015). In this respect, they have highlighted the importance to study Circular Economy, both from a perspective of environmental governance paradigms - such as the Ellen MacArthur Foundation $(2014,2015)$ and complementary studies do and suggest (Haas, et al., 2015) - and from a social science (or environmental psychology) perspective (Gregson \& Crang, 2015). And this particularly with the aim to underline that an important effort is required to policymakers in promoting a public awareness on Circular Economy, as already mentioned, which also addresses the different attitudes and values of individuals to more proactive behaviors in front of recycle and reuse practices (Xue, et al., 2010; Guo, et al., 2017). In addition, several scientific contributions (Geng, et al., 2012, 2013) highlight the relevance for policymakers to leverage on performance indicators for Circular Economy that look beyond the processes or products to encompass a more holistic view of the concept of Circular Economy at company level.

Finally, literature on product design practices has looked into the Circular Economy paradigm by emphasizing the pivotal role played by the activities of design for recycling (DfR), design for remanufacturing and reuse (DfR), design for disassembly (DfD) and design for environment (DfE) (Mayyas, et al., 2012; Go, et al., 2011; Goldsworthy, 2014; Dagman \& Söderberg, 2012). The implementation of these practices by companies allow extending the life span of products, by using less resources and materials, and maintaining them at their highest value at any point of the products' life cycles, as well as rethinking the ways, processes and capabilities through which products are engineered and commercialized to final customers. Accordingly, these practices are extensively indicated as measurement items for evaluating Circular Economy in practice (see, e.g., Zhu, et al., 2010). 


\subsubsection{Circular Economy in the strategic management field}

Very few contributions frame the topic of Circular Economy as a paradigm that companies can implement from a business model perspective (Linder \& Williander, 2015; Vermeulen, 2015; Crainer, 2013). In particular, Linder \& Williander (2015) assess empirically the influence of several drivers hampering the implementation of Circular Economy Business Models, i.e. the typologies of different customers who have different needs, the technological expertise of companies, the portfolio of products, as well as operational risks and of cannibalization, the fashion vulnerability, the capital tied up and the incentives for partners. On the other hand, Vermeulen (2015) identifies a set of implications for individual businesses in order to adapt or change their business model with the current macrotrends on global markets, such as continuing population growth and growth of unhealthy megacities, increasing volume of human consumption and carbon-based energy system, which influences climatechange and impacts environment and society. In this respect, Circular Economy Business Models of companies should base on reducing the dependence on virgin materials, shift from a carbon-based energy system to a renewable one, increase the adoption of sustainable production practices and adjust their value chain strategies. Finally, Crainer (2013) highlights the critical role for companies to reinvent themselves according to the Circular Economy framework, by conceiving the waste from their business activities as something to be designed within their corporate strategies and "metabolized" in the same economy.

However, these contributions do not study the degree of adoption of Circular Economy, i.e. they are still written under a Boolean on or off approach, and do not discuss how firms can in practice adapt their business model to this new paradigm. Hence, as suggested by the same scholars (Linder \& Williander, 2015; Vermeulen, 2015; Crainer, 2013), this opens avenues for further theoretical and empirical research.

\subsection{The Business Model perspective}

A Business Model represents a set of strategic decisions that defines how companies create, transfer, and capture value according to their internal activities and relationships with stakeholders, among which suppliers and customers (Afuah \& Tucci, 2001; Osterwalder, et al., 2005; Zott, et al., 2011; Osterwalder \& Pigneur, 2013). For several years, literature on strategic management has studied the role of the Business Model as a means to shape the strategy of companies. Indeed, the Business Model represents for companies a driver of competitiveness, defining how to position in the market against competitors. Accordingly, managers consider the design of the Business Model 
as a strategic priority for their companies (Chesbrough, 2007, 2010; Ireland, et al., 2001). Moreover, the discussion about how the Business Model concept can support management in defining and developing the company's strategy is still opened as highlighted by a recent study of Spieth, et al. (2014). However, among the several representations of a company's business model (Chesbrough \& Rosenbloom, 2002; Zott \& Amit, 2010; Osterwalder, 2004; Bocken, et al., 2014), we took into account the Business Model Canvas (Osterwalder, 2004). His Canvas is a reference framework, when several scientific contributions have used it in their empirical analyses (Fritscher \& Pigneur, 2009; Meertens, et al., 2012; Muhtaroglu, et al., 2013; Zolnowski, et al., 2014; Vargas, et al., 2015; Joyce \& Paquin, 2016), with nine building blocks according to that companies can represent their business. 


\section{Theoretical Framework and Empirical Analysis}

\subsection{Theoretical Framework: A New Taxonomy of Circular Economy Business Models}

Based on the existing literature on Circular Economy and Business Model presented above, we argue that the adoption of a Circular Economy model, as it happens for any new industrial paradigm, requires firms to adapt their business model or create a new one (Mathews \& Tan, 2011; Yang \& Feng, 2008).

In a circular economy, the linear flow of "resources - products - waste", typical of traditional business models of companies, is replaced by the new pattern "resources - productswaste - renewable resources". From a business model perspective, this implies that:

i. To the typical activities of the forward supply chain, i.e. planning, purchase of raw materials, production, marketing and distribution (necessary to make finished products available to the final consumers), firms need to add and manage the activities of the reverse supply chain, i.e. the reverse logistics, the inspection and evaluation of products' current state, their redistribution/reuse, remanufacturing and recycling (Bakker, et al., 2014; Dalhammar, 2016; Matsumoto, et al., 2016).

The adoption of the practices above requires new technological equipment and skills. At a strategic level, for example, companies should adopt a systemic approach in order to understand where the value is created in the supply chain and the role in the value creation of the entire network of suppliers, manufacturers, retailers and customers. In addition, the knowledge of Life Cycle Assessment (LCA) (Mayyas, et al., 2012; Geng, et al., 2013; Vadoudi, et al., 2014; Deviatkin, 2016) and Product Lifecycle Management (PLM) (Salonitis \& Stavropoulos, 2013; Vadoudi, et al., 2014; Popa \& Popa, 2014) practices increase their relevance, playing a pivotal role in those firms adopting the Circular Economy.

ii. The value proposition of firms in circular economies should consist in the offering of product-service systems (PSSs), which are, as suggested by Tukker and Tischner (2006), “ $a$ mix of tangible products and intangible services designed and combined so that they jointly are capable of fulfilling final customer needs".

The idea, in this case, is to satisfy customers' needs by offering products with low physical contents. This implies customers to be no longer owners of products, but users, and companies to become service providers. By doing so, the property of products remains in the hands of the 
producers. In addition, the value of products is no longer represented by the price, but by the number of functional units that they are able to provide in the lifecycle. In this way, Circular Economy becomes a functional economy, where customers pay for the use of products and not for their possession, as well as the physical product and technology become the vehicles to provide a function. Furthermore, firms in Circular Economy have incentive to design products with extensive lifecycle, which consume the least amount of resources and energy during their use phases, and which are suitable to be disassembled and recovered at the end of life (Mont, 2002).

iii. Even the relationships with customers change, as in Circular Economy they consist in a higher number of interactions, mostly enabled by leasing and rental contracts.

Firms in Circular Economy get more insights on preferences and purchasing habits of customers and offer a more enhanced experience. This also facilitates the degree of retention and maintenance of their customer-base over time until the creation of a brand-based and cooperative community (Zhu, et al., 2011).

iv. Finally, the flow of revenues, i.e. how much customers pay for products or services, mainly derive from the payment for use-oriented or result-oriented services, which encompass the above-mentioned transition from a "pay-per-own" to a "pay-per-use" approach (Tukker, 2004).

The former include, for example, the leasing or rental/sharing services, whereas the latter refer to pay-per-use services. The implementation of a closed supply chain model would allow decreasing the amount of virgin material purchased and the amount of energy needed for its transformation, with a consequent reduction of input costs. In addition, the recovery of materials and products would avoid them the landfills, saving the related disposal costs (Stahel, 2016). This is of particular interest for firms due to the increase of disposal costs and of stringent regulations, and for the fact that available spaces in landfills are running low (Ellen MacArthur Foundation, 2013).

As it emerges from the research dealing with Circular Economy in companies' business model, four main modifications are required by companies to adapt or create a new business model according to the principles of Circular Economy. In particular, these modifications require, on the one hand, to implement reverse supply chain activities and a higher degree of cooperation with the actors of the supply chain, and on the other hand, a new value proposition for customers, 
which requires a new way to perceive the buying process and a higher degree of cooperation between companies and customers themselves.

These four business model modifications can be clustered into two dimensions of the Business Model Canvas framework that we depict hereafter (Figure 1):

\begin{tabular}{|c|c|c|c|}
\hline $\begin{array}{l}\text { (i) } \\
\text { Reverse supply chain } \\
\text { activities and higher } \\
\text { degree of cooperation } \\
\text { with the actors of the } \\
\text { supply chain }\end{array}$ & $\begin{array}{c}\text { (ii) } \\
\text { Transition from a } \\
\text { "pay-per-own" to a } \\
\text { "pay-per-use" } \\
\text { approach }\end{array}$ & $\begin{array}{c}\text { (iii) } \\
\text { Higher degree of } \\
\text { cooperation between } \\
\text { companies and } \\
\text { customers }\end{array}$ & $\begin{array}{l}\text { (iv) } \\
\text { Payment for use- } \\
\text { oriented or result- } \\
\text { oriented services }\end{array}$ \\
\hline Value network & \multicolumn{3}{|c|}{ Customer value proposition \& interface } \\
\hline
\end{tabular}

Figure 1. Circular Economy in companies' business model.

Accordingly, we assume in our study that the Business Model Canvas framework introduced above explains in each of two major dimensions, (i) the customer value proposition $\&$ interface and (ii) the value network, the degree of circularity of companies from a business model perspective.

(i) The customer value proposition \& interface defines the implementation of the circularity concept in proposing value to customers and how it determines the positioning of companies against competitors in the market according to their customers segments, relationship, distribution channels and value proposition (Zott, et al., 2011; Osterwalder \& Pigneur, 2013). From a Circular Economy perspective, this dimension is relevant only if the firms make visible to customers their compliance with the principle of Circular Economy that becomes part of their positioning against competitors. This implies asking questions such as "How much the firm makes visible in its products the circular practices that implements?", or "How much the price that the customer pays is based on the pay-peruse or in general on the Circular Economy approach?" The variables that we used to measure this dimension are Price and Promotion (Heerde, et al., 2013). In particular, Price means the different ways through which the value is offered to customers, i.e. if it is based on use rather than on ownership and it is by function rather than by product (Williams, 2007; Tukker, 2004, 2015; Tukker

\& Tischner, 2006; Mont, 2002). Promotion means how the firm promotes content based on circularity within its marketing campaigns (Heerde, et al., 2013). This means creating awareness to customers about the educational, ethical and economic value of products realized with the 
implementation of product design practices, and incentivizing them to their adoption through commercial initiatives, direct involvement and extensive communication of Circular Economy principles (Kumar \& Venkatesan, 2005; Baxendale, et al., 2015; Rampton, 2015). In order to provide an objective and transparent description of the customer value proposition $\&$ interface dimension, we have explained Price and Promotion in terms of specific features ensuing from the marketing literature. Accordingly, Table 1 provides the features of Price and Promotion variables that explain the characterization of the customer value proposition $\&$ interface dimension.

Table 1. Criterion of characterization of the customer value proposition \& interface.

\begin{tabular}{|c|c|c|c|}
\hline Variables & Features & $\begin{array}{l}\text { Degree of } \\
\text { Circularity }\end{array}$ & Main references \\
\hline \multirow{4}{*}{ Price } & $\begin{array}{l}\text { Sale of single } \\
\text { products }\end{array}$ & Low & \multirow{4}{*}{$\begin{array}{c}\text { Williams, } 2007 \\
\text { Tukker, 2004, } 2015 \\
\text { Tukker \& Tischner, } 2006 \\
\text { Mont, } 2002 \\
\text { Stahel, } 2016\end{array}$} \\
\hline & $\begin{array}{l}\text { Sale of products with } \\
\text { additional } \\
\text { complementary } \\
\text { services } \\
\text { (maintenance, } \\
\text { financing, take-bake } \\
\text { programs) }\end{array}$ & Medium-Low & \\
\hline & Leasing/Renting & Medium-High & \\
\hline & $\begin{array}{l}\text { Pay-per-use or } \\
\text { functional result }\end{array}$ & High & \\
\hline \multirow{4}{*}{ Promotion } & $\begin{array}{c}\text { Information on } \\
\text { companies website }\end{array}$ & Low & \multirow{4}{*}{$\begin{array}{c}\text { Kumar \& Venkatesan, } 2005 \\
\text { Baxendale, et al., } 2015 \\
\text { Rampton, } 2015\end{array}$} \\
\hline & $\begin{array}{l}\text { Communication in } \\
\text { store through } \\
\text { advertising and sales } \\
\text { personnel }\end{array}$ & Medium-Low & \\
\hline & $\begin{array}{c}\text { Direct customer } \\
\text { involvement in } \\
\text { circularity initiatives }\end{array}$ & Medium-High & \\
\hline & $\begin{array}{c}\text { Communication of } \\
\text { circularity through all } \\
\text { channels }\end{array}$ & High & \\
\hline
\end{tabular}


Therefore, as far as Price variable is concerned, the degree of circularity increases passing from a kind of sale that involves single products to a sale of product-oriented services (i.e. products with additional complementary services), to a sale of use-oriented products (i.e. leasing or renting), until a sale of result-oriented products (i.e. pay-per-use or functional result). On the other hand, the degree of circularity increases, considering the Promotion dimension, whether companies implement particular promotion initiatives - such as the creation of community or providing testing services of the product - which involve directly the customer, or they recourse simultaneously to a variety of touchpoints to communicate the circularity of their business. Promotional contents that are available independently on the websites of companies and companies that perform in-store communications or inter-personal forms of communication concern a low (i.e. low or medium-low) degree of circularity.

(ii) The value network defines the ways through which companies interact with their suppliers and reorganize their own internal activities, i.e. the key resources, activities, and upstream partners (Osterwalder \& Pigneur, 2013). From a circular perspective, this dimension aims at measuring what and how many are the circular operational practices adopted in the internal activities of the company. The variables we used to measure this dimension are the degree of implementation of Design for Recycling (DfR), Design for Remanufacturing and Reuse (DfRe), Design for Disassembly (DfD) and Design for Environment (DfE) practices by the firms, with the idea sustained by literature that the larger is the degree of adoption of circular practices in the design phase, the larger is the number of suppliers involved (Mayyas, et al., 2012; Go, et al., 2011; Goldsworthy, 2014; Dagman \& Söderberg, 2012). These practices are extensively indicated as measurement items for evaluating Circular Economy in practice (e.g., Zhu, et al., 2010) and therefore particularly suitable in our analysis to define the value network dimension. In this case, the role of suppliers as those key partners in providing renewable, recyclable or biodegradable resources and materials as inputs of production systems for the implementation of these practices is fundamental (Zhu, et al., 2011; Vermeulen, 2015). In order to provide an objective and transparent description of the value network dimension, we have used specific features ensuing from the literature dealing with the adoption of circular practices in the remanufacturing industry (Parkinson \& Thompson, 2003). Accordingly, Table 2 provides the features that explain the characterization of the value network dimension. 
Table 2. Criterion of characterization of the value network.

\begin{tabular}{|c|c|c|}
\hline Features & Degree of Circularity & Main references \\
\hline $\begin{array}{l}\text { Focus on energy efficiency: } \\
\text { reduction of emissions and } \\
\text { environmental footprint }\end{array}$ & Low & \multirow{4}{*}{$\begin{array}{c}\text { Parkinson \& Thompson, } 2003 \\
\text { Zhu, et al., } 2010 \\
\text { Mayyas, et al., } 2012 \\
\text { Go, et al., } 2011 \\
\text { Goldsworthy, } 2014 \\
\text { Dagman \& Söderberg, } 2012\end{array}$} \\
\hline $\begin{array}{l}\text { Focus on materials: natural, } \\
\text { recyclable, durable, easy to } \\
\text { separate }\end{array}$ & Medium-Low & \\
\hline $\begin{array}{l}\text { Focus on DfR, DfRe, DfD, } \\
\text { DfE: modularity, } \\
\text { standardization, ease of } \\
\text { disassembly, designed for } \\
\text { recycling, LCA }\end{array}$ & Medium-High & \\
\hline $\begin{array}{c}\text { Focus on materials and } \\
\text { implementation of one or more } \\
\text { of DfX practices }\end{array}$ & High & \\
\hline
\end{tabular}

Therefore, companies that implement practices of DfX or in the case in which the application of ad hoc DfX practices is accompanied by a careful use of materials - which means a selection of key suppliers that provide the right resources and materials as inputs of production systems - in their internal activities, have a high (i.e. medium-high or high) degree of circularity.

By crossing the two dimensions above, we propose the following taxonomy that identifies four modes of adoption of Circular Economy by companies with significant differences among each other according to the magnitude of the variables that define the degree of circularity of the value network or the customer value proposition $\&$ interface (Figure 2). 


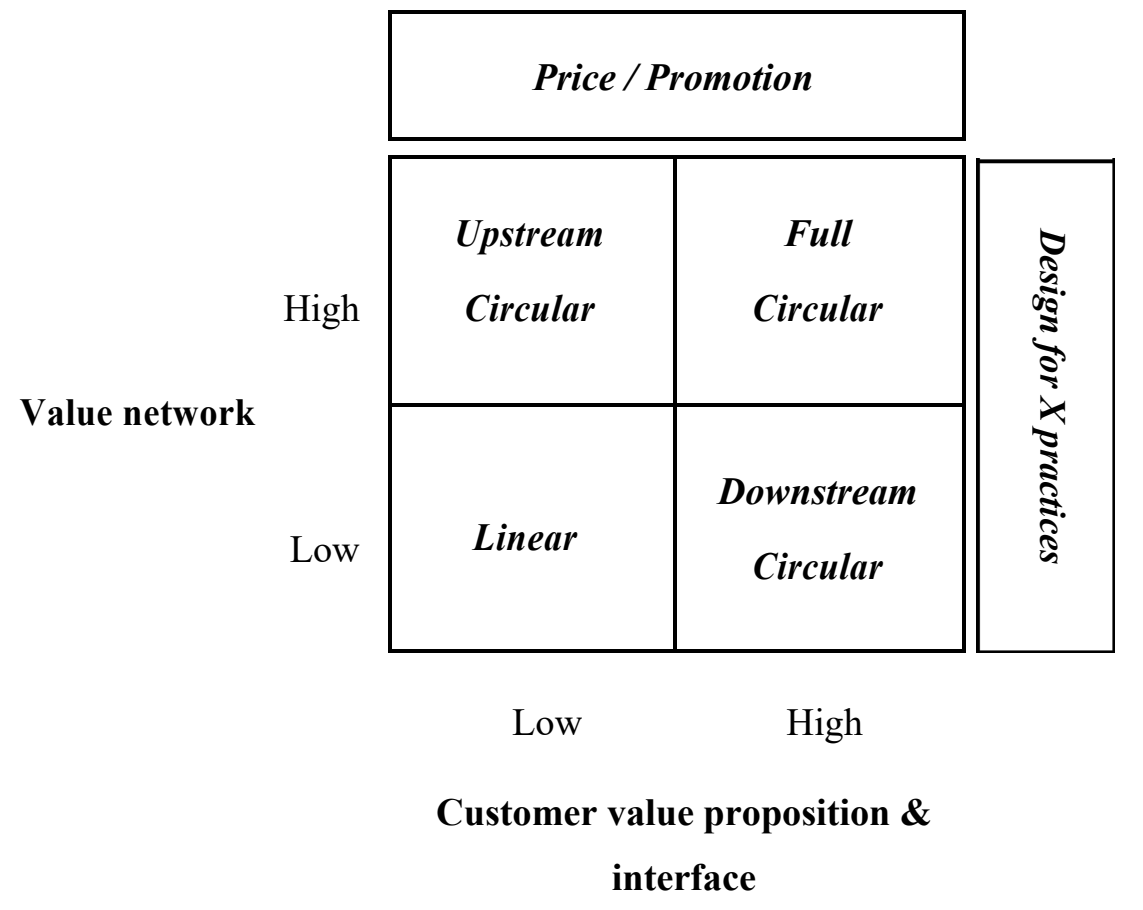

Figure 2. The four available modes to adopt Circular Economy principles.

Indeed:

1. The Downstream Circular adoption mode concerns firms that adopt a price scheme or a marketing campaign that is based on the "use" and "re-use" of products, but where internal practices and design procedures for products do not seem to reflect the characteristics of a circular "adopter". In this way, the firm is focusing on the market acceptance of the pay-per-use model whereas not relevant changes are made at the level of product design, internal activities or suppliers. In this case, the focus of Downstream Circular companies is on the revenue stream and the advantage is tied to the market penetration;

2. The Upstream Circular adoption mode concerns firms that adopt circular principles in their product design activities and eventually establish effective relationship with new suppliers, but that do not make visible to their final customers, neither on the price or in the marketing campaigns their adoption of Circular Economy. In this case, contrary to what happens before, the focus of Upstream Circular companies is on the cost structure and the advantage is tied to the cost efficiency; 
3. The Full Circular adoption mode concerns firms that are circular both internally and externally. In particular, this kind of firms, not only manages the production system according to the principles of Circular Economy, but also the involvement of suppliers in its circular production system is relevant and effective. Moreover, these firms communicate clearly to customers the implementation of circular practices in their internal activities because this is considered of value.

Therefore, the taxonomy was further tested on our first, exploratory empirical setting, as described in the next section.

\subsection{Empirical Analysis}

\subsubsection{Mapping the Sample of Companies from Secondary Sources}

We needed to design an exploratory empirical analysis to test the ability of our taxonomy to properly distinguish and explain in practice the existence of different modes of adoption of Circular Economy by firms.

We focused only on those companies adopting in different extent the principles of Circular Economy. To have a reliable set of cases, even if based on secondary sources, we decided to consider the case studies listed and recorded on the Ellen MacArthur Foundation website. 24 firms operating in different sectors of activity, which have adopted the principles of Circular Economy, were present in the list, which is also shown in Table 3.

Table 3. List of the 24 firms on the Ellen MacArthur Foundation website (accessed at the latest the April 17, 2016).

\begin{tabular}{|c|c|}
\hline Firm & Sector of Activity \\
\hline Superuse Studios & Built Environment \\
\hline Aquafil & Chemistry \\
\hline Brocklesby & Chemistry \\
\hline Kalundborg Symbiosis & Cross Sector \\
\hline Reep Technologies Ltd. & Electronic and Electrical Equipment \\
\hline Gamestop & Electronic and Electrical Equipment \\
\hline Mazuma Mobile & Electronic and Electrical Equipment \\
\hline
\end{tabular}




\begin{tabular}{|c|c|}
\hline Philips \& Turntoo 6 & Electronic and Electrical Equipment \\
\hline Agency of Design & Electronic and Electrical Equipment \\
\hline Bundles & Electronic and Electrical Equipment \\
\hline Re-tek & Electronic and Electrical Equipment \\
\hline Furnishare & Fabrics Apparel Carpets Textiles \\
\hline Desso & Fabrics Apparel Carpets Textiles \\
\hline Mud Jeans & Fabrics Apparel Carpets Textiles \\
\hline Rype Office & Fabrics Apparel Carpets Textiles \\
\hline Ecovative & Fast Moving Consumer Goods \\
\hline Splosh & Fast Moving Consumer Goods \\
\hline Coca Cola Enterprises & Fast Moving Consumer Goods \\
\hline Braiform & Fast Moving Consumer Goods \\
\hline Floow2 & Information and Technology \\
\hline Refuse Vehicle Solution Ltd. & Machinery and Automotive \\
\hline Autocraft Drivetrain Solutions & Machinery and Automotive \\
\hline Maersk Line & Machinery and Automotive \\
\hline Caterpillar & Machinery and Automotive \\
\hline
\end{tabular}

Afterwards, in order to enlarge data and information of the sampled cases where testing our taxonomy, we analysed as primary sources journals, websites, magazines and reports that have described these companies from a circular perspective. The most helpful and frequently referenced sources of information were Bloomberg, The Economist, The Financial Times, The Wall Street Journal, and the European Commission website. We have supported our research with professional full-text journal databases such as InfoTrac and LexisNexis. In addition, the choice to take additional data and information from secondary sources aimed at facilitating crosscase comparisons and triangulation of information. In this respect, a content analysis (Weber, 1990) was performed on the collected material, in order to cluster the information contained in the documents.

Then, we strengthened the empirical analysis by adding an appropriate list of organisations from the Circular Economy 100 members $^{7}$, i.e. "a pre-competitive innovation programme established to enable organisations to develop new opportunities and realise their circular

\footnotetext{
${ }^{6}$ It is important to underline that Philips \& Turntoo means a collaborative project for a pioneering 'Payper-lux' model.

${ }^{7}$ https://www.ellenmacarthurfoundation.org/ce100/directory.
} 
economy ambitions faster. It brings together corporates, governments and cities, academic institutions, emerging innovators and affiliates in a unique multi-stakeholder platform. Specially developed programme elements help members learn, build capacity, network, and collaborate with key organisations around the circular economy".

By taking into account this list, we eliminated those organisations that did not fit with our taxonomy on the basis of the following criteria:

1. Ineffective description on the identified secondary sources that did not allow for a clear understanding of the degree of adoption of Circular Economy principles;

2. Different logics of business model design among organisations, such as in the case of companies versus institutions or public administrations;

3. Firms already on the list of Table 3.

As a consequence, the second round of analysis involved 62 firms operating in different sectors of activity, which have adopted in different extent the principles of Circular Economy. The list of these firms is shown in Table 4.

Table 4. List of the 62 firms from the Circular Economy 100 members.

\begin{tabular}{|c|c|}
\hline Firm & Sector of activity \\
\hline AeroFarms & Agriculture \\
\hline Anaerobic Digestion and Biogas Association \\
(ADBA) & Chemicals \\
\hline Antea Group U.S.A, INC & Energy \\
\hline bio-bean Ltd & Transport and Logistics \\
\hline Brambles & Built Environment \\
\hline Building Research Establishment (BRE) & Telecommunications \\
\hline BT Group PLC & Eesearch and Professional Services \\
\hline C2C Institute $\&$ ICT \\
\hline Cisco Systems Ltd & Recovery of Products and Materials \\
\hline Closed Loop & Recovery of Products and Materials \\
\hline Center for Remanufacturing \& Reuse (CRR) & Financial services and Investment \\
\hline De Lage Landen (DLL) & EEE \& ICT \\
\hline Dell & Built Environment \\
\hline Delta Development Group & Transport and Logistics \\
\hline DHL & \\
\hline
\end{tabular}




\begin{tabular}{|c|c|}
\hline Ebay & Software and Online Services \\
\hline Environcom England Ltd & Recovery of Products and Materials \\
\hline Envotherm A/S & Recovery of Products and Materials \\
\hline Google & Software and Online Services \\
\hline Granta Design & Software and Online Services \\
\hline Hewlett Packard & EEE \& ICT \\
\hline H\&M & Retail \\
\hline HSSMI & Research and Professional Services \\
\hline iFixit & Software and Online Services \\
\hline Ikea & Furniture, Textile and Flooring ; Retail \\
\hline Innoverne & Software and Online Services \\
\hline Intesa Sanpaolo & Financial services and Investment \\
\hline Kingfisher & Retail \\
\hline Lexmark & EEE \& ICT \\
\hline Lithium Balance A/S & Energy \\
\hline Marks and Spencer $(\mathrm{M} \& \mathrm{~S})$ & Retail \\
\hline Michelin & Automotive and transport manufacturing \\
\hline Midal Cables & Industrial machinery and equipment \\
\hline National Grid & Energy \\
\hline Noble Environmental Technologies & Built Environment, Manufacturing, Materials \\
\hline Novelis & Materials \\
\hline Orange & Telecommunications \\
\hline PGGM & Financial services and Investment \\
\hline Ragn-Sells & Recovery of Products and Materials \\
\hline Recoup & Recovery of Products and Materials \\
\hline Renault France & Automotive and transport manufacturing \\
\hline Replenish & FMCG \& Packaging \\
\hline Rocky Mountain Institute & Research and Professional Services \\
\hline Royal Bam Group & Built Environment \\
\hline Royal DSM & Chemicals \\
\hline Schiphol Nederland B.V. & Transport and Logistics \\
\hline Schneider Electric & Energy \\
\hline Selfrag & Industrial machinery and equipment \\
\hline Solum Gruppen & Agriculture \\
\hline Steelcase & Furniture, Textile and Flooring \\
\hline Stuffstr & Software and Online Services \\
\hline
\end{tabular}




\begin{tabular}{|c|c|}
\hline Suez Environment & Recovery of Products and Materials \\
\hline SunPower & Energy \\
\hline Tarkett GDL & Furniture, Textile and Flooring \\
\hline TerraCycle & Recovery of Products and Materials \\
\hline Tetra Pak & FMCG \& Packaging \\
\hline Unilever & FMCG \& Packaging \\
\hline Veolia Environment & Recovery of Products and Materials \\
\hline Vigga & Furniture, Textile and Flooring \\
\hline Vodafone Group & Telecommunications \\
\hline WRAP & Research and Professional Services \\
\hline ZeroBin & Transport and Logistics \\
\hline
\end{tabular}

Also in this case, we have gathered additional data and information by using the same journals, websites, magazines and reports used in the first round of analysis that have described these companies from a circular perspective.

Therefore, our empirical analysis was divided in a first-tier analysis, which involves 24 firms, and in a second-tier analysis, which involves 62 firms. Therefore, the sample included a total of 86 firms operating in different sectors of activity, which have adopted in different extent the principles of Circular Economy.

\subsubsection{The involvement of Circular Economy experts}

As last step, in practice, a panel of Italian experts of Circular Economy - among which 2 consultants, 3 researchers and 3 professors - was assembled in order to position all the companies of our sample in our taxonomy. Accordingly, in order to implement this phase, our panel of experts used the criteria of characterization - of the customer value proposition $\&$ interface and the value network - highlighted before.

To achieve this goal, we leveraged on a traditional Delphi tool, as it is particularly suitable to obtain a reliable convergence of opinions on a particular issue by a group of experts, avoiding the negative effects of their direct interaction and face-to-face (Geist, 2010), and for classification or taxonomy development (Okoli \& Pawlowski, 2004), as in our case.

Accordingly, the Delphi procedure (Geist, 2010; Okoli \& Pawlowski, 2004; Delbecq, et al., 1975) was articulated as in the following phases: 
1. We designed a document, where we initially presented the project and its main goals. Therefore, we highlighted our taxonomy and the variables (price, promotion, and design for $\mathrm{X}$ practices) that explain the dimensions of (i) value network and (ii) customer value proposition $\&$ interface. Therefore, again, we explicitly pointed out, as indication for our experts for positioning the sampled companies, to follow rigorously the criteria of characterization of (i) the value network and (ii) the customer value proposition \& interface dimensions, built upon the features of each variable (price, promotion and design for $\mathrm{X}$ practices).

2. We selected an appropriate group of experts following the guidelines of Delbecq, et al. (1975), who invite to involve individuals with different perspectives, although with a valuable knowledge, on a same issue. Indeed, we involved 2 consultants, with a more practitioner-oriented view, 3 researchers, with a more scientific-oriented view, and 3 professors, with a broader view on both directions. Although existing research in this field recommends to involve among 10 and 18 experts (Okoli \& Pawlowski, 2004), the topic of Circular Economy in the strategic management field is rather emerging so to justify a slightly smaller number of individuals involved.

3. Finally, a multiple-step iterative approach, which consisted in managing the sending and receiving of document by each expert, analysing the responses, asking clarifications of the answers, and asking other questions based on the experts' feedbacks, was conducted, until a stable and reliable convergence of positioning of the sampled companies. 


\section{Results and discussions}

The following Figure 3 presents the results of applying our taxonomy by our panel of Italian experts of Circular Economy to the cases above, once combining the first- and second-tiers after a triangulation of information for both.

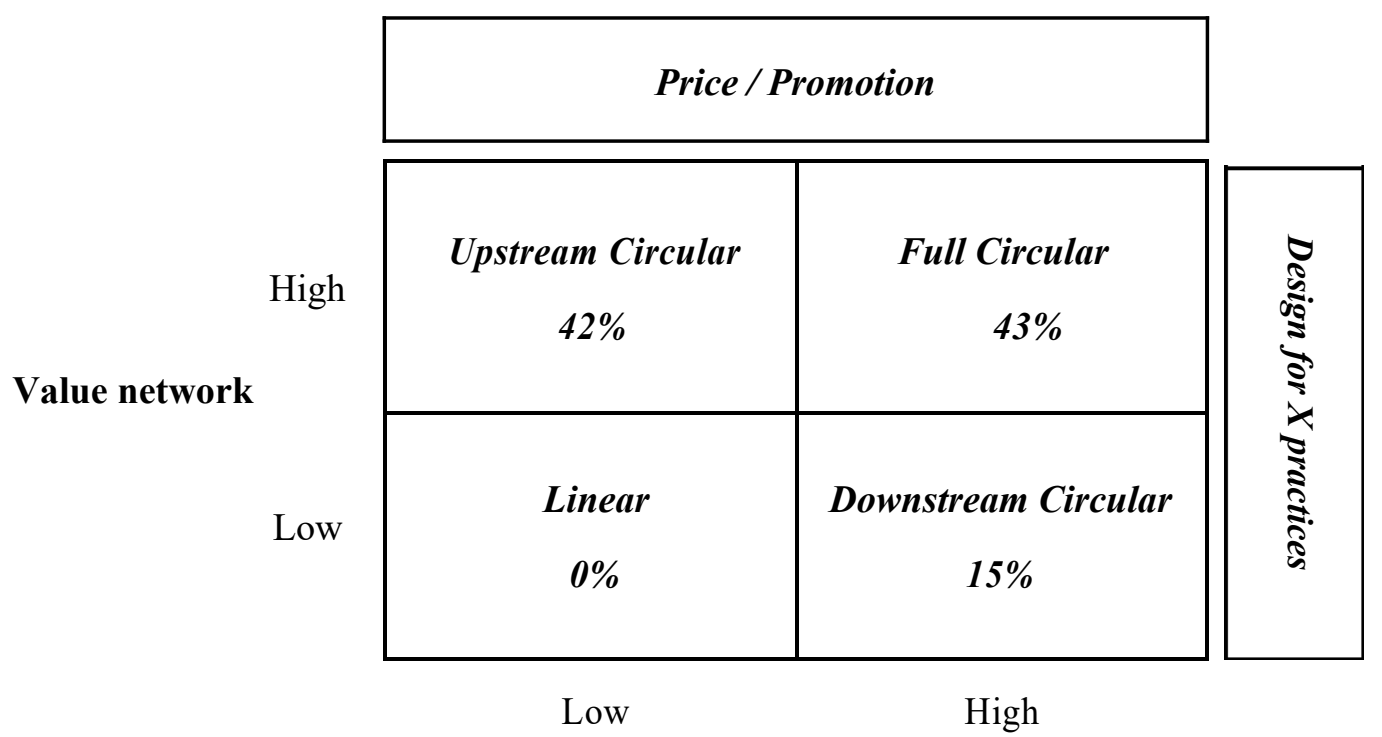

\section{Customer value proposition \& \\ interface}

Figure 3. Firms of the empirical analysis mapped by our panel of experts according to the theoretical framework.

According to the positioning made by our panel of experts of Circular Economy, our taxonomy properly distinguish and explain in practical contexts different modes of adoption of Circular Economy by companies.

First, even if the sample was based on the lists present in the Ellen MacArthur Foundation, the Full Circular firms are less than half of the sample, more precisely they are around the $43 \%$, once combining after a triangulation of information both tiers.

Full Circular firms directly adopt principles of Circular Economy in their internal activities and relationships with suppliers, as well as in their customer value proposition $\&$ interface. In particular, these firms invest heavily in marketing campaigns to advertise their circular value proposition, such as Mazuma Mobile, as well as in R\&D activities to create new supply chains, such as Tetra Pak. In particular, they aim at developing ad hoc communication platforms and programmes, such as Superuse Studios, Delta and Orange, or to explicitly incentivize customers to adopt themselves a 
circular approach, such as TerraCycle. This is consistent with extant literature about the way companies redesign their value proposition and customer interface for adopting Circular Economy (Williams, 2007; Tukker, 2004, 2015; Tukker \& Tischner, 2006; Mont, 2002; Heerde, et al., 2013; Kumar \& Venkatesan, 2005; Baxendale, et al., 2015; Rampton, 2015). In particular, TerraCycle is "the world leader in the collection and recycling of otherwise non-recyclable post-consumer waste. In 24 countries, through nationally-operated voluntary collection programmes, TerraCycle recycles pens, toothbrushes, candy wrappers, cosmetic bottles, cigarette butts and many other waste streams". What makes this company circular is, on the downstream side, the intense customers' engagement, leveraging on long-term global recycling programmes for their waste, which is otherwise nonrecyclable. In addition, the company has developed excellent in-house marketing and communications teams and is adding new business units to provide options for end-users, among which distributors, institutions and individuals, to purchase recycling customized services. On the upstream side, TerraCycle reverse engineers' "planned obsolescence" represents a virtuous cycle between the brands, which finance the above mentioned recycling programmes, the retailers, who benefit from in-store collection programs sponsored by the brands, and the customers themselves. Full Circular firms involve a high number of partners in their internal activities to enhance the value of products and minimize as much as possible the production of waste and energy consumption (such as Coca Cola Enterprises, Antea Group U.S.A, INC and DLL). This is also consistent with extant literature about the way companies redesign their supply chain and relationship with partners (Vermeulen, 2015; Parkinson \& Thompson, 2003; Zhu, et al., 2011).

The second most frequent typology of firms in the sample is the Upstream Circular, i.e. those firms that work more on the internal and network dimension of the Circular Economy making most of their effort not even visible to the customer. Even if they belong to many different sectors, there is a certain prevalence of firms in hard manufacturing industries. In these cases, like for Renault, Replenish and bio-bean Ltd, the transition for the ownership concept to the usage still suffers a lot of inertia from the final customer. Renault, for example, represents the main icon in the automotive and transport manufacturing industry for the reuse and recycle of materials in its manufacturing processes. The company aims at reducing the environmental footprint of its vehicles by increasing their durability, maintaining them during their lifecycle, and reintroducing spare parts of the vehicles in the supply chain once they reach the phase of decline. On the other hand, Replenish, operating in the FMCG and packaging industry of USA, attempts to eliminate the waste of plastic bottles by providing to brands and companies reusable packaging-bottles that are designed to mix liquid concentrate refill pods with water. If we consider that in USA 35 billion of plastic bottles are thrown away each year instead of being recycled, Replenish contributes to save money along the whole 
supply chain starting from the upstream phases. Finally, bio-bean Ltd, an emerging innovator in the UK energy industry, aims at recycling waste coffee grounds into carbon-neutral advanced biofuel. The company contributes in adding value and sustainability in the supply chains of coffee companies, by providing technologies and solutions that directly tackle coffee waste starting from the upstream phases. Moreover, in most of these cases, a secondary market already exists, taking care of products after the initial owner ends its period of use of the product. Assuming a Full Circular approach in such cases would mean to displace a number of actors already existing and with established relationships with the producers, and with no clear roles in a completely circular way of functioning of the industry.

Finally, Downstream Circular firms mainly are intermediary platforms offering products in a Circular Economy approach, e.g., by developing business-to-business (B2B) or business-tocustomers (B2C) sharing marketplaces, which enable companies to communicate each other for exchanging underutilized goods. In this case, Kalundborg Symbiosis, Furnishare and Floow2 are representative examples of Downstream Circular firms. For example, Kalundborg Symbiosis allow public and private companies to sell and buy waste of industrial production from each other in a circular manner. Indeed, wastes of a company, such as steam, ash, gas, heat or sludge, can become raw materials for another one that belongs to the platform. On the other hand, Furnishare, operating in the Fabrics Apparel Carpets Textiles industry as a B2C platform, allows people to donate their unwanted or underutilized items and monetize from selling them to other people instead of dispose of. Finally, Floow2, the Luxembourg company operating in the software and online services industry, attempts to reduce the overcapacity of goods by matching the demand and offering of companies within the platform. In particular, a company can rent or buy the goods it needs directly from another firm that is in the platform. This allows companies to interact in a closed way with the possibility of making their business more circular.

In addition, it is worth adding to the previous point, a remark about the fact that exogenous factors - such as the size, the industry, the geography and the age of the company - seem not to matter in the adoption process and to explain how and why companies could belong to determined quadrants of the theoretical framework.

Indeed, if it is true that Downstream Circular firms are usually the smallest and youngest in the sample, Full Circular and Upstream Circular firms can be either big companies, with more years of activity, which reckon in the adoption of Circular Economy a high value for them and their customers, or new ventures born to exploit the potential of circular business models. In this respect, Gamestop, Mud Jeans, Splosh, Caterpillar, Closed Loop, Dell, Recoup, Solum Gruppen and 
Unilever are representative examples. Accordingly, Gamestop is a big company operating in the electronic and electrical equipment industry that creates value for itself by adopting refurbishing and recycling model for its software/video games and other kinds of electronics, as well as by continuously developing trade programs for its customers. In a similar way, Caterpillar adopts principles of circularity in its internal activities by replacing products before they break and rebuilding them with a mixture of new and used components. At the same time, Caterpillar communicates to its customers the implementation of circular practices in its processes because the company considers this of a high value, although customer understanding and perception remains sometimes the key problem. Indeed, as highlighted by the managing director, "People think it means washed, painted, repaired, second hand and so on. It's a challenge to convince and educate the consumer that they're getting the same performance at 50-60\% of the cost of new'. On the other hand, the emerging innovator Solum Gruppen provides compost, growth media and turf for the Danish agriculture supply chain, by converting discarded organic resources into valuable biogas and fertilizer. Similarly, Recoup, operating in the recovery of products and materials industry, works across the entire supply chain to promote good practice, provide information and aid the sustainable development of UK plastic recycling.

On the contrary, based on the observations and discussion above, it seems that the adoption of Circular Economy, mainly depend on the willingness of companies, i.e. the management commitment, to adopt Circular Economy principles by emphasizing more a dimension or another of the business model.

In particular, from the cases above, it emerges how the different way with which companies are pushed towards a cost efficiency or towards a revenue stream explains the Upstream and Downstream modes of adoption of Circular Economy by firms. In addition, the actual Downstream mode of adoption of Circular Economy seems to play the critical role of interface in order to extract values from the markets. On the other hand, the entire access to the circular approach, i.e. the Full mode of adoption of Circular Economy, is not enough diffused, and this leaves us thinking on the willingness of managers to overcome the barriers of implementation of Circular Economy Business Models (see, i.e., Linder \& Williander, 2015), which are quite recognizable in the cases of Upstream and Downstream Circular companies.

Accordingly, we additionally argue whether and how the propensity of the management to adopt Circular Economy practices could play a pivotal role in avoiding these barriers and finally allow the shift towards Circular Economy Business Models. 


\section{Conclusions}

The paper explores the adoption of Circular Economy under the lens of the business model literature and proposes a new taxonomy that explains different degrees of circularity in practice adopted by firms in different industries. In particular, we focus the distinction of Circular Economy Business Models on the differences emerging on two major dimensions: the (i) customer value proposition $\&$ interface, i.e. the implementation of the circularity concept in proposing value to customers; the (ii) value network, i.e. the ways through which interacting with suppliers and reorganizing the own internal activities.

Accordingly, the paper highlights four available modes of adoption of Circular Economy, i.e. Linear, Upstream Circular, Downstream Circular and Full Circular. Our map of circular modes of adoption seems to properly distinguish different ways through which companies establish their Circular Economy Business Models, i.e. how they leverage on Circular Economy principles from a business model perspective.

In particular, it appears that these modes are not directly linked in a temporal fashion, potentially representing patterns of evolution of firms and industries in adopting the Circular Economy. Rather, they seem to represent just different modes of adoption of Circular Economy principles, which mainly depend on the willingness of the company, i.e. the management commitment, to adopt Circular Economy principles. Particularly in this case, we point out the need to for future theoretical and empirical research to analyze the influence of the managerial commitment in formulating and establishing circular-oriented policies and objectives, training internal resources and creating awareness on the need of product design practices among all the actors of the supply chain, as well as overseeing their implementation at all company-levels and revising the programs and initiatives in the light of the circularity results achieved.

In addition, we argue how exogenous factors - such as the size, the industry, the geography and the age of the company - do not seem to matter in the adoption process and to explain how, whether and why companies belong to a specific quadrant or to another of our theoretical framework. This is particularly interesting if we think that exogenous factors have historically always guided the shaping of the business model of companies in a given sector of activity (see, i.e., Porter, 1979). Accordingly, we invite future theoretical and empirical research to analyse whether in the case of Circular Economy the contextual factors could have in some extent an impact in terms of shaping Circular Economy Business Models. 
Notwithstanding, the sample that we used for the empirical analysis was not sufficiently big to clarify the influence of the management commitment in the adoption process of circular practices by companies. Therefore, we argue that this could be a good point to start new theoretical and empirical research in order to explore and understand the internal reasons that push management of companies to embrace or not Circular Economy principles and overcome the existing barriers of adoption.

In addition, the empirical evidence used in the paper is only explorative in nature and therefore in this respect further effort is needed. In particular, the explorative nature of the paper highlights two important limitations that have to be tackled by future research. On the one hand, from the point view of the empirical setting, as because companies in our sample stem from secondary sources and they are very heterogeneous each other, i.e. they differ for industry, country, dimension, and positioning along the value chain. This issue calls for establishing a more homogeneous sample of companies in order to capture differences and similarities in the dimensions of value network and customer value proposition \& interface of their Circular Economy Business Model more effectively. On the other hand, from a theoretical perspective, our discussion on the temporal fashion and on the influence of the exogenous factors in shaping Circular Economy Business Models, i.e., the size, the industry, the geography and the age of the company, is built upon (and after) the positioning of the sampled companies in our taxonomy. This means that the temporal fashion and the exogenous factors are not considered ex-ante in our study, but they result from ex-poste considerations, so they cannot be generalized to any population of companies or industries, but requiring ad hoc research.

In addition, we retain that a panel of managers operating in several of the above mentioned companies, who have role of responsibilities in the supply chain management, manufacturing and sustainability activities, need to be involved in order to clarify the dimensions and variables influencing their positioning on our taxonomy.

However, we believe that our contribution to the debate in the field of Circular Economy and strategic management provides scholars with a valuable taxonomy to test, modify and refine in order to better classify and distinguish companies complying with the implementation of Circular Economy principles to shift towards a Circular Economy Business Model. 


\section{References}

Accenture. (2014). Circular Advantage. Innovative Business Models and Technologies to Create Value in a world without Limits to Growth.

Afuah, A., Tucci, C.L. (2001). Internet business models and strategies: Text and cases. New York: McGraw-Hill.

Bakker, C., Wang, F., Huisman, J., den Hollander, M. (2014). Products that go round: exploring product life extension through design. Journal of Cleaner Production, 69, 10-16.

Baxendale, S., Macdonald, E.K. and Wilson, H.N. (2015). The Impact of Different Touchpoints on Brand Consideration. Journal of Retailing, 91(2), 235-253.

Besio, C., Pronzini, A. (2014). Morality, ethics, and values outside and inside organizations: An example of the discourse on climate change. Journal of Business Ethics, 119, 287-300.

Bocken, N.M.P., Short, S.W., Rana, P., Evans, S. (2014). A literature and practice review to develop sustainable business model archetypes. Journal of Cleaner Production, 65, 42-56.

Chertow, M., Ehrenfeld, J. (2012). Organizing Self-Organizing Systems. Journal of Industrial Ecology, 16(1), 13-27.

Chesbrough, H. (2007). Business model innovation: it's not just about technology anymore. Strategy \& Leadership, 35(6), 12-17.

Chesbrough, H. (2010). Business Model Innovation: Opportunities and Barriers. Long Range Planning, 43(2-3), 354-363.

Chesbrough, H., Rosenbloom, R.S. (2002). The role of the business model in capturing value from innovation: evidence from Xerox Corporation's technology spin-off companies. Industrial and Corporate Change, 11(3), 529-555.

Cooper, T. (1999). Creating an economic infrastructure for sustainable product design. Journal of Sustainable Design, 8, 7-17.

Crainer, S. (2013). Squaring the circle. Business Strategy Review, 24(4), 13-19.

Dagman, A., and Söderberg, R. (2012). Toward a Method for Improving Product Architecture Solutions by Integrating Designs for Assembly, Disassembly and Maintenance. ASME 2012 International Mechanical Engineering Congress and Exposition. American Society of Mechanical Engineers.

Dalhammar, C. (2016). Industry attitudes towards ecodesign standards for improved resource efficiency. Journal of Cleaner Production, 123, 155-166.

De los Rios, I. C., Charnley, F. J. (2017). Skills and capabilities for a sustainable and circular economy: The changing role of design. Journal of Cleaner Production, 160, 109-122.

Delbecq, A.L., Van de Ven, A.H., Gustafson, D.H. (1975). Group Techniques for Program Planning: A Guide to Nominal Group and Delphi Processes. Scott Foresman and Company, Glenview, Illinois.

Dell Recycling. Available at: http://www.dell.com/learn/us/en/uscorp1/dell-environmentrecycling? $\mathrm{s}=$ corp. 
Deviatkin, I., Kapustina, V., Vasilieva, E., Isyanov, L., Horttanainen, M. (2016). Comparative life cycle assessment of deinking sludge utilization alternatives. Journal of Cleaner Production, 112, 3232-3243.

Ellen MacArthur Foundation. (2013). Towards the Circular Economy Vol. 2: opportunities for the consumer goods sector.

Ellen MacArthur Foundation. (2014). Toward the Circular Economy Vol.3: Accelerating the scale-up across global supply chains.

Ellen MacArthur Foundation. (2015). Circularity Indicators: An approach to Measuring Circularity.

Feng, Z.J., Yan, N.L. (2007). Putting a circular economy into practice in China. Sustainability Science, 2 , 95-101.

Fernandez, J.E. (2007). Resource consumption of new urban construction in China. Journal of Industrial Ecology, 11(2), 99-115.

Fischer, A., Pascucci, S. (2017). Institutional incentives in circular economy transition: The case of material use in the Dutch textile industry. Journal of Cleaner Production, 155(2), 17-32.

Fritscher, B., Pigneur, Y. (2009). Supporting business model modelling: A compromise between creativity and constraints. In International Workshop on Task Models and Diagrams for User Interface Design (pp. 28-43). Springer Berlin Heidelberg.

Geist, M.R. (2010). Using the Delphi method to engage stakeholders: A comparison of two studies. Evaluation and Program Planning, 33(2), 147-154.

Geng, Y., Zhang, P., C`ot'e, R.P., Qi, Y. (2008). Evaluating the applicability of the Chinese eco-industrial park standard in two industrial zones. International Journal of Sustainable Development and World Ecology, 15, 1-10.

Geng, Y., Zhu, Q., Doberstein, B., Fujita, T. (2009). Implementing China's circular economy concept at the regional level: A review of progress in Dalian, China. Waste Management, 29(2), 996-1002.

Geng, Y., Fu, J., Sarkis, J., Xue, B. (2012). Towards a national circular economy indicator system in China: an evaluation and critical analysis. Journal of Cleaner Production, 23(1), 216-224.

Geng, Y., Sarkis, J., Ulgiati, S., Zhang, P. (2013). Measuring China's circular economy. Science, 339(6127), 1526-1527.

Geng, Y., Sarkis, J., Ulgiati, S. (2016). Sustainability, well-being, and the circular economy in China and worldwide. Science, special issue on Pushing the boundaries of scientific research: 120 years of addressing global issues, 76-79.

Gerrard, J., Kandlikar, M. (2007). Is European end-of-life vehicle legislation living up to expectations? Assessing the impact of the ELV Directive on 'green' innovation and vehicle recovery. Journal of Cleaner Production, 15(1), 17-27.

Go, T.F., Wahab, D.A., Rahman, M.A., Ramli, R., Azhari, C.H. (2011). Disassemblability of end-of-life vehicle: a critical review of evaluation methods. Journal of Cleaner Production, 19(13), 1536-1546.

Goldsworthy, K. (2014). Design for Cyclability: pro-active approaches for maximising material recovery. Making Futures, 3, 1-12. 
Gregson, N., Crang, M. (2015). From waste to resource: the trade in wastes and global recycling economies. Annual Review of Environment and Resources, 40, 151-176.

Guo, B., Geng, Y., Sterr, T., Zhu, Q., Liu, Y. (2017). Investigating public awareness on circular economy in western China: A case of Urumqi Midong. Journal of Cleaner Production, 142, 2177-2186.

Haas, W., Krausmann, F., Wiedenhofer, D., \& Heinz, M. (2015). How circular is the global economy? An assessment of material flows, waste production, and recycling in the European Union and the world in 2005. Journal of Industrial Ecology, 19(5), 765-777.

Heerde, H.J.V., Gijsenberg, M.J., Dekimpe, M.G., Steenkamp, J.B.E. (2013). Price and advertising effectiveness over the business cycle. Journal of Marketing Research, 50(2), 177-193.

Hu, J., Xaio, Z., Deng, W., Wang, M., Ma, S. (2011). Ecological utilization of leather tannery waste with circular economy model. Journal of Cleaner Production, 19, 221-228.

Ireland, R.D., Hitt, M.A., Camp, S.M., Sexton, D.L. (2001). Integrating entrepreneurship and strategic management actions to create firm wealth. Academy of Management Executive, 15(1), 49-63.

Joyce, A., Paquin, R. L. (2016). The triple layered business model canvas: a tool to design more sustainable business models. Journal of Cleaner Production, 135, 1474-1486.

Area, 47(1), 16-23.

Kumar, V., and Venkatesan, R. (2005). Who are the multichannel shoppers and how do they perform?:

Correlates of multichannel shopping behaviour. Journal of Interactive Marketing, 19(2), 44-62.

Li, H.Q., Bao, W.J., Xiu, C.H., Zhang, Y., Xu, H.B. (2009). Energy conservation and circular economy in China's process industries. Energy, 35(1111), 4273-4281.

Li, Y., Ma, C. (2015). Circular economy of a papermaking park in China: a case study. Journal of Cleaner Production, 92, 65-74.

Linder, M., Williander. M. (2015). Circular Business Model Innovation: Inherent Uncertainties. Business Strategy and the Environment, 26(2), 182-196.

Lombardi, D.R., Lyons, D., Shi, H., \& Agarwal, A. (2012). Industrial symbiosis. Journal of Industrial Ecology, 16(1), 2-7.

Ma, S.H., Wen, Z.G., Chen, J.N., Wen, Z.C. (2014). Mode of circular economy in China's iron and steel industry: a case study in Wu'an city. Journal of Cleaner Production, 64, 505-512.

Mathews, J.A., Tan, H. (2011). Progress towards a circular economy in China: The drivers (and inhibitors) of eco-industrial initiative. Journal of Industrial Ecology, 15, 435-457.

Matsumoto, M., Yang, S., Martinsen, K., Kainuma, Y. (2016). Trends and research challenges in remanufacturing. International Journal of Precision Engineering and Manufacturing-Green Technology, 3(1), 129-142.

Mattila, T., Lehtoranta, S., Sokka, L., Melanen, M., Nissinen, A. (2012). Methodological aspects of applying life cycle assessment to industrial symbioses. Journal of Industrial Ecology, 16(1), 51-60. 
Mayers, C.K., France, C.M., Cowell, S.J. (2005). Extended producer responsibility for waste electronics: An example of printer recycling in the United Kingdom. Journal of Industrial Ecology, 9(3), 169-189. Mayyas, A., Qattawia, A., Omara, M., Shana, D. (2012). Design for Sustainability in Automotive Industry: A Comprehensive Review. Renewable and Sustainable Energy Reviews, 16, 1845-1862.

McDonough, W., Braungart, M. (2002). Cradle to Cradle: remaking the way we make things. New York: North Point.

McGlyn, J. (2015). 5 megatrends that will unleash value in the circular economy. GreenBiz. Available at: http://www.greenbiz.com/article/5-megatrends-will-unleash-value-circular-economy.

McKinsey. (2011). Resource Revolution: Meeting the World's Energy, Materials, Food, and Water needs. McKinsey Global Institute.

Meertens, L.O., Iacob, M.E., Nieuwenhuis, L.J., Van Sinderen, M.J., Jonkers, H., Quartel, D. (2012). Mapping the business model canvas to archimate. In Proceedings of the 27th annual ACM symposium on applied computing (pp. 1694-1701). ACM.

Miliute-Plepiene, J., Plepys, A. (2015). Does food sorting prevents and improves sorting of household waste? A case in Sweden. Journal of Cleaner Production, 101, 182-192.

Mont, O. (2002). Functional Thinking: The role of functional sales and product service systems for a function-based society.

Muhtaroglu, F.C.P., Demir, S., Obali, M., Girgin, C. (2013). Business model canvas perspective on big data applications. In Big Data, 2013 IEEE International Conference on (pp. 32-37). IEEE.

Murray, A., Skene, K., Haynes, K. (2017). The Circular Economy: An Interdisciplinary Exploration of the concept and Application in a Global Context. Journal of Business Ethics, 140(3), 369-380.

Okoli, C., Pawlowski, S.D. (2004). The Delphi method as a research tool: an example, design considerations and applications. Information \& Management, 42(1), 15-29.

Osterwalder, A. (2004). The business model ontology: A proposition in a design science approach.

Osterwalder, A., Pigneur, Y. (2013). Business model generation: a handbook for visionaries, game changers, and challengers. John Wiley \& Sons.

Osterwalder, A., Pigneur, Y., Tucci, C.L. (2005). Clarifying business models: Origins, present, and future of the concept. Communications of the AIS, 16(1), 1-25.

Parkinson, H.J., Thompson, G. (2003). Analysis and taxonomy of remanufacturing industry practice. Proceedings of the Institution of Mechanical Engineers, Part E: Journal of Process Mechanical Engineering, 217(3), 243-256.

Pintér, L. (2006). International Experience in Establishing Indicators for the Circular Economy and Considerations for China. Report for the Environment and Social Development Sector Unit, East Asia and Pacific Region. The World Bank, Washington.

Popa, I.L., Popa, N.V. (2014). PLM and Eco-Design of Electronic Products According with Circular Economy Principles. Applied Mechanics and Materials, 657, 1031-1035.

Porter, M.E. (1979). How competitive forces shape strategy. Harvard Business Review. 
Preston, F. (2012). A global redesign? Shaping the circular economy. Energy, Environment and Resource Governance, 2, 1-20.

Rampton, J. (2015). 8 Ways To Engage Better With Your Customers. Forbes. Available at: www.forbes.com/sites/johnrampton/2015/09/14/8-ways-to-engage-better-with-your-customers/.

Richter, J.L., Koppejan, R. (2016). Extended producer responsibility for lamps in Nordic countries: best practices and challenges in closing material loops. Journal of Cleaner Production, 123, 167-179.

Salonitis, K., Stavropoulos, P. (2013). On the integration of the CAx systems towards sustainable production. Procedia CIRP, 9, 115-120.

Schneider, A. (2015). Reflexivity in sustainability accounting and management: Transcending the economic focus of corporate sustainability. Journal of Business Ethics, 127, 525-536.

Spieth, P., Ricart, J.E., Schneckenberg, D. (2014). Business model innovation - state of the art and future challenges for the field. R\&D Management Journal, 44, 237-247.

Stahel, W.R. (2016). The circular economy. Nature, 531(7595), 435-438.

Su, B., Heshmati, A., Geng, Y., Yu, X. (2013). A review of the circular economy in China: moving from rhetoric to implementation. Journal of Cleaner Production, 42, 215-227.

Subramoniam, R., Huisingh, D., Chinnam, R.B. (2009). Remanufacturing for the automotive aftermarketstrategic factors: literature review and future research needs. Journal of Cleaner Production, 17(13), 1163-1174.

Tukker, A. (2004). Eight types of product-service system: eight ways to sustainability? Experiences from SusProNet. Business Strategy and the Environment, 13, 246-260.

Tukker, A. (2015). Product services for a resource-efficient and circular economy - A review. Journal of Cleaner Production, 97, 76-91.

Tukker, A., Tischner, U. (2006). Product-services as a research field: past, present and future. Reflections from a decade of research. Journal of Cleaner Production, 14, 1552-1556.

UNEP. (2006). Circular Economy: An alternative for economic development. Paris: UNEP DTIE.

Vadoudi K., Allais R., Reyes T., Troussier N. (2014) Sustainable Product Lifecycle Management and

Territoriality: New Structure for PLM. In: Fukuda S., Bernard A., Gurumoorthy B., Bouras A. (eds) Product Lifecycle Management for a Global Market. PLM 2014. IFIP Advances in Information and Communication Technology, 442. Springer, Berlin, Heidelberg

Vargas, I.S., Calva, A.L.G., Camacho, J.H. (2015). Business model canvas. Ciencias Huasteca Boletín Cientifico de la Escuela Superior de Huejutla, 3(5), 1-6.

Vermeulen, W.J. (2015). Self-Governance for Sustainable Global Supply Chains: Can it Deliver the Impacts Needed?. Business Strategy and the Environment, 24(2), 73-85.

Weber, R.P. (1990). Basic content analysis. Newbury Park, CA: Sage.

Williams, A. (2006). Product-service systems in the automotive industry: the case of micro-factory retailing. Journal of Cleaner Production, 14(2), 172-184. 
Williams, A. (2007). Product service systems in the automobile industry: contribution to system innovation? Journal of Cleaner Production, 15, 1093-1103.

Xue, B., Chen, X. P., Geng, Y., Guo, X. J., Lu, C. P., Zhang, Z. L., Lu, C. Y. (2010). Survey of officials' awareness on circular economy development in China: Based on municipal and county level. Resources, Conservation and Recycling, 54(12), 1296-1302.

Yang, S., Feng, N.A (2008). Case study of industrial symbiosis: Nanning Sugar Co., Ltd. in China. Resources, Conservation and Recycling, 52(5), 813-820.

Yu, C., Davis, C., Dijkema, G.P. (2014). Understanding the evolution of industrial symbiosis research. Journal of Industrial Ecology, 18(2), 280-293.

Yuan, Z., Bi, J, Moriguichi, Y. (2006). The circular economy: A new development strategy in China.

Zhu, Q., Geng, Y., Lai, K. H. (2010). Circular economy practices among Chinese manufacturers varying in environmental-oriented supply chain cooperation and the performance implications. Journal of Environmental Management, 91(6), 1324-1331.

Zhu, Q., Geng, Y., Lai, K.H. (2011). Environmental Supply Chain Cooperation and Its Effect on the Circular Economy Practice-Performance Relationship Among Chinese Manufacturers. Journal of Industrial Ecology, 15(3), 405-419.

Zolnowski, A., Weiß, C., Bohmann, T. (2014). Representing Service Business Models with the Service Business Model Canvas - the Case of a Mobile Payment Service in the Retail Industry. In system sciences (HICSS), 47th Hawaii International Conference on (pp. 718-727). IEEE.

Zott, C., Amit, R. (2010). Business model design: an activity system perspective. Long range planning, 43(2), 216-226.

Zott, C., Amit, R., Massa, L. (2011). The business model: Recent developments and future research. Journal of Management, 37(4), 1019-1042. 


\section{Notation list}

[1] http://www.ellenmacarthurfoundation.org/circular-economy/interactive-diagram/thecircular-economy-applied-to-the-automotive-industry.

[2] http://about.hm.com/en/About/sustainability/commitments/reducewaste/garment-collecting.html.

[3] http://www.dell.com/learn/us/en/uscorp1/dell-environment-recycling?s=corp.

[4] http://www.prnewswire.com/news-releases/patagonia-launches-common-threads-initiative-apartnership-with-customers-to-consume-less-129372068.html.

[5] https://connect.innovateuk.org/web/collaborations-circular-economy.

[6] It is important to underline that Philips \& Turntoo means a collaborative project for a pioneering 'Pay-per-lux' model.

[7] https://www.ellenmacarthurfoundation.org/ce100/directory. 